\title{
A Novel Performance Analysis of the Microstrip Antenna Printed on a Cylindrical Body
}

\author{
Amr M. Mahros, ${ }^{1,2}$ Marwa M. Tharwat, ${ }^{3}$ and Ali Elrashidi ${ }^{4}$ \\ ${ }^{1}$ Department of Physics, King Abdulaziz University, Jeddah 21432, Saudi Arabia \\ ${ }^{2}$ Department of Engineering Physics, Alexandria University, Alexandria 21544, Egypt \\ ${ }^{3}$ Department of Electrical \& Computer Engineering, King Abdulaziz University, Jeddah 21432, Saudi Arabia \\ ${ }^{4}$ Department of Electrical Engineering, University of Business and Technology, Jeddah 21432, Saudi Arabia
}

Correspondence should be addressed to Amr M. Mahros; amr.mahros@mena.vt.edu

Received 30 September 2014; Revised 22 November 2014; Accepted 23 November 2014; Published 11 December 2014

Academic Editor: Jaume Anguera

Copyright (C) 2014 Amr M. Mahros et al. This is an open access article distributed under the Creative Commons Attribution License, which permits unrestricted use, distribution, and reproduction in any medium, provided the original work is properly cited.

Performance of a circular patch microstrip antenna is highly affected by the effective dielectric constant of a used substrate material. When the circular patch is conformed on a cylindrical body, the effective dielectric constant is changing with curvature due to the changing in the fringing field. Consequently, some of antenna parameters such as resonance frequency, input impedance, voltage standing wave ratio, return loss, quality factor, and antenna bandwidth are functions of curvature. In this work, we study the effect of curvature on the performance of circular patch microstrip antenna. A mathematical model for the antenna parameters as functions of curvature is also introduced. The model is applied in case of using two substrates of different refractive index values. By extension, the antenna performance was studied through simulation by using method of moments (MoM) which is reliable in solving Maxwell's integral equations in the frequency domain. The results from simulation compare very favorably with the described analytical results.

\section{Introduction}

Circular patch microstrip antenna is widely used in recent wireless applications such as aircraft communications, Bluetooth, HIPERLAN, and medical imaging [1-4]. A microstrip antenna has received extensive research due to its low cost and small size. This antenna can be easily fabricated and conformed on cylindrical bodies [5-7].

Conformal antennas, in general, have some advantages over planner microstrip antennas such as wide angular coverage and controlled gain $[8,9]$. The main drawback of microstrip antennas is their narrow bandwidth which results in high sensitivity to any frequency change and decreases the efficiency of their overall performance [10].

In this paper, we introduce the effect of curvature of a conformed circular microstrip printed antenna on the effective dielectric constant, resonance frequency, input impedance, voltage standing wave ratio (VSWR), return loss $\left(S_{11}\right)$, quality factor, and bandwidth of such antenna. Furthermore, the mathematical equations for these parameters as functions of curvature for cylindrical surface are also reported in this paper. The analysis is considered at resonance frequency of $2.4 \mathrm{GHz}$ and transverse magnetic mode $\mathrm{TM}_{01}$ for two different substrate materials with dielectric constants of 2.1 and 10 . Though it was mentioned that changing the radius of curvature of a cylindrical body has no effect on the resonance frequency of a circular patch microstrip antenna printed on a cylindrical body, the experimental results show a bit shift on the operating frequency for different curvature [11]. The debate emerged as there is no clear explanation for this shift that had been introduced.

We have introduced comprehensive mathematical equations that show the effect of curvature of a cylindrical body on a rectangular microstrip printed antenna [12]. The theoretical results were compared to experimental results to verify the introduced model.

In this work, we extend the model to study the curvature effect on a circular patch microstrip antenna printed on 


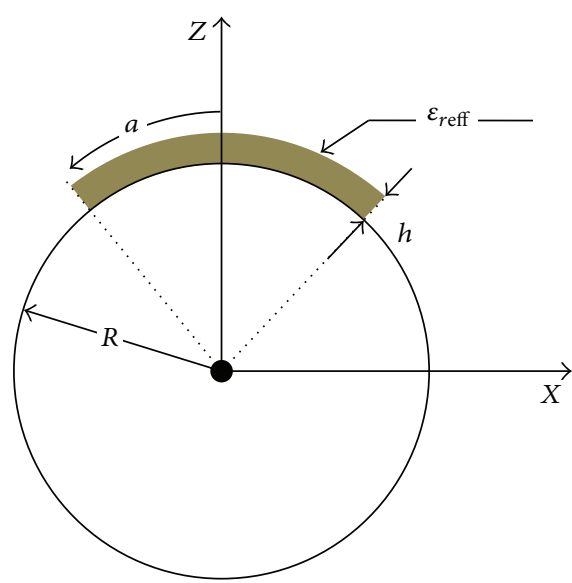

Figure 1: Cylindrical-circular patch microstrip printed antenna geometry [16].

a cylindrical surface. The fringing field effect on the performance of a conformal circular patch antenna is also presented in this paper.

In the rectangle microstrip printed antenna, the effective dielectric constant, depending on fringing field, is varying with curvature and microstrip patch length [12]. However, in circular patch microstrip antenna, it depends on the distance between the central axis and the microstrip edge. The value of that distance is varying from zero to the circular patch radius.

The cylindrical-circular patch microstrip antenna is very famous and popular in many military applications [13]. The circular patch microstrip antenna has a number of advantages over the rectangular one. It has a symmetric radiation pattern, higher directivity, smaller VSWR, and higher return loss [14].

The resonance frequency $f_{010}$ for $\mathrm{TM}_{01}$ mode as a function of an effective radius of antenna $a_{\text {eff }}$ and effective dielectric constant $\varepsilon_{\text {reff }}$ has been presented by Balanis as [11]

$$
f_{010}=\frac{3.8318 \times c}{2 \pi a_{\mathrm{eff}} \sqrt{\varepsilon_{\mathrm{eff}}}},
$$

where $c$ is the speed of light.

Luk and Lee studied the curvature effect on the performance of circular disc microstrip antenna conformed on a cylindrical body, as shown in Figure 1, for $\mathrm{TM}_{01}$ [15]. Quality factor, input impedance, and power are introduced for different values of curvatures. The authors noted that all studied parameters are functions of curvature except the operating frequency, according to their model. In their model, the authors did not consider the fringing filed effect on the antenna parameters and the effect of radius of curvature on effective dielectric constants.

A mathematical model for input impedance and far electric field of a coaxial fed circular patch microstrip printed antenna conformed on a cylindrical surface was introduced using cavity model by Luk and Lee [16]. The fringing filed effect on an effective circular patch radius and on an effective dielectric constant is considered in this paper. However, the curvature effects on the resonance frequency and on fringing field itself were not considered.
Mathematical and experimental results for a slot coupled cylindrical-circular microstrip antenna for input impedance as a function of curvature using cavity model were introduced in [11]. The mathematical model assumed that there is no change in resonance frequency, but the experimental results showed a little shift in frequency due to curvature. A physical explanation for this experimental result had never been given. We have introduced the first physical explanation of this shift in frequency in [17]. The curvature effects on the effective dielectric constant and consequently on the operating frequency as cleared from (1) are introduced in [18].

\section{The Proposed Model}

The fringing field effect of a microstrip line on the effective dielectric constant is firstly introduced by Wheeler in 1961 [19]. Appling this model, we have produced an expression of the dielectric constant as a function of radius of curvature for a rectangular microstrip printed antenna conformed on a cylindrical surface [20]. Starting from Maxwell's equations, expressions for electric and magnetic fields intensities, quality factor, input impedance, VSWR, and return loss are obtained as a function of radius of curvature [21].

Here, we extend our work and study the performance of a conformal circular patch antenna.

First, we obtained dielectric constant $\varepsilon_{\text {reff }}$ for different curvatures, as shown in [20], and then substituted the dielectric constant in (1) to get the resonance frequency for $\mathrm{TM}_{01}$ as a function of curvature. In this case, the electric field components $E_{\theta}$ and $E_{\varphi}$ for a far field are obtained as shown below:

$$
\begin{gathered}
E_{\theta}=E_{0} \frac{e^{-j k_{0} r}}{\pi r} \sum_{n=-\infty}^{\infty} e^{j n \emptyset} j^{n+1} f_{n}\left(-k_{0} \cos \theta\right), \\
E_{\emptyset}=-E_{0} \frac{\omega \mu \epsilon e^{-j k_{0} r}}{\mu_{0} \pi r} \sum_{n=-\infty}^{\infty} e^{j n \emptyset} j^{n+1} g_{n}\left(-k_{0} \cos \theta\right),
\end{gathered}
$$

where

$$
\begin{aligned}
f_{n}= & \frac{j \omega \varepsilon_{0} \int_{-\infty}^{\infty} M(n, p) e^{-j n \emptyset} e^{-j p z} d z}{\left(k_{0}^{2}-n^{2}\right) H_{p}^{2}\left(a \sqrt{k_{0}^{2}-n^{2}}\right)}, \\
g_{n}= & \frac{\int_{-\infty}^{\infty} M(n, p) e^{-j n \emptyset} e^{-j p z} d z}{\left(\sqrt{k_{0}^{2}-n^{2}}\right) H_{p}^{\prime 2}\left(a \sqrt{k_{0}^{2}-n^{2}}\right)} \\
& \times\left(\frac{n p}{a\left(k_{0}^{2}-n^{2}\right)}-1\right) .
\end{aligned}
$$

$M(n, p)$ is the equivalent magnetic currents along the circumference of the circular path, $\omega$ is the angular frequency, and $k_{0}=\omega_{0} \sqrt{\mu \epsilon_{0}}$.

Boundary conditions were applied on the elementary wave function. So, the homogenous wave vanishes at edges and satisfies the normalized conditions. Then, coaxial feed is considered as a rectangular current source with equivalent cross-sectional area $S z \times S_{\Phi}$ centered at $\left(Z_{0}, \Phi_{0}\right)$. 


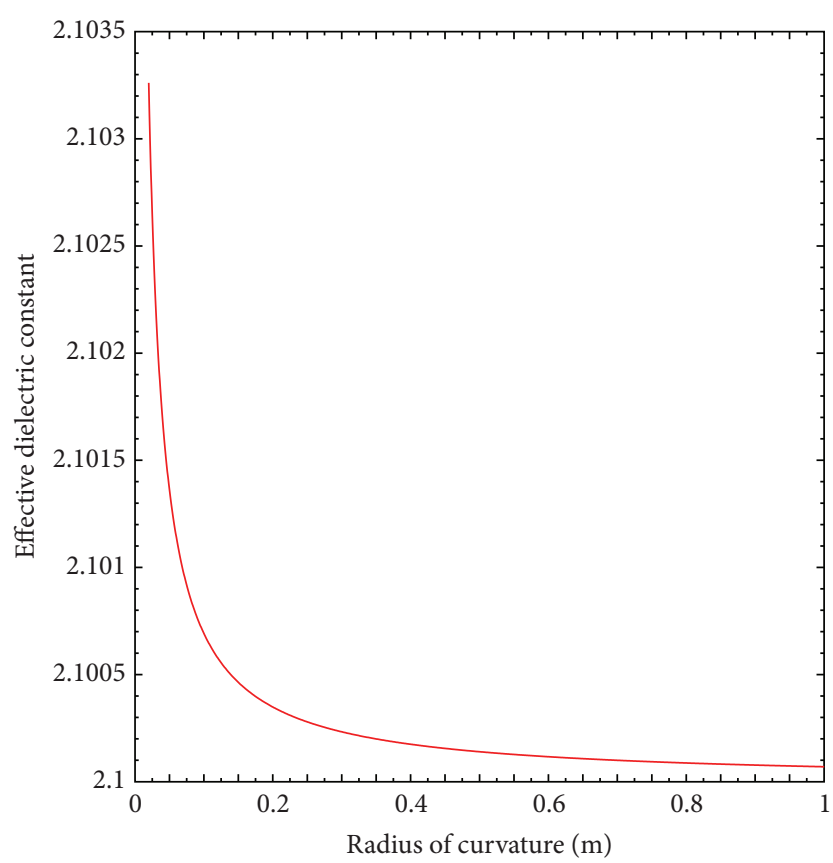

(a)

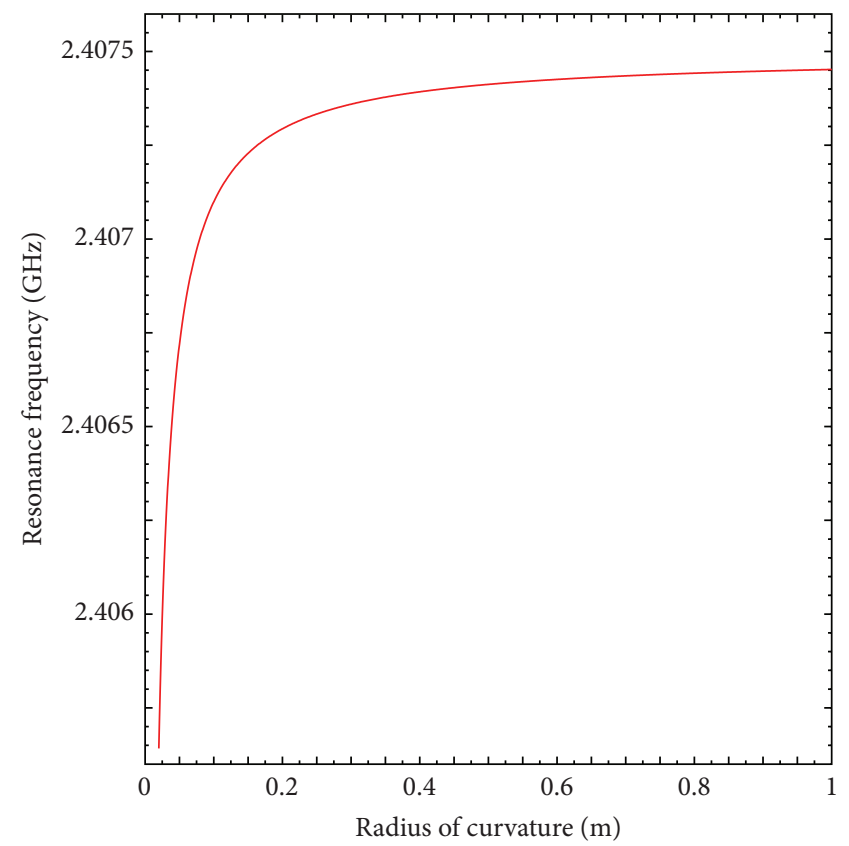

(b)

FIGURE 2: Impact of changing radius of curvature of a circular microstrip patch (a) on the effective dielectric constant and (b) on the resonance frequency. "Teflon substrate."

Input impedance as function of effective dielectric constant $\varepsilon_{\text {reff }}$ and position of feeding $\left(Z_{0}\right.$ and $\left.\Phi_{0}\right)$ is defined as

$$
\begin{aligned}
Z_{\text {in }}= & j \omega \mu h \sum_{n} \sum_{m} \frac{1}{k_{0}^{2}-k^{2}} \frac{R \varepsilon_{\text {reff }}}{2 a_{\mathrm{eff}}^{3}} \times \cos ^{2}\left(\frac{\pi}{a_{\mathrm{eff}}} z_{0}\right) \\
& \times \sin c\left(\frac{\pi}{2 a_{\mathrm{eff}}} z_{0}\right) \sin c\left(\frac{R \pi}{2 a_{\mathrm{eff}}^{2}} \emptyset_{0}\right) .
\end{aligned}
$$

The total quality factor depends on the conduction quality factor $Q_{c}$, dielectric loss quality factor $Q_{d}$, and radiation quality factor $Q_{\text {rad }}$ as given in

$$
\begin{gathered}
\frac{1}{Q_{t}}=\frac{1}{Q_{\mathrm{rad}}}+\frac{1}{Q_{c}}+\frac{1}{Q_{d}}, \\
Q_{c}=h \sqrt{\pi f \mu \sigma}, \\
Q_{d}=\frac{1}{\tan \delta}, \\
Q_{\mathrm{rad}}=\frac{2 \omega \varepsilon_{r}}{h G_{t}} K,
\end{gathered}
$$

where $K$ and $G_{t}$ are given in [11].

The bandwidth $\mathrm{BW}$ is given by

$$
\mathrm{BW}=\frac{f_{0}}{\mathrm{Q}_{t}}
$$

and hence the VSWR values as a function of curvature can be calculated as

$$
\Delta f=f_{0} \frac{\mathrm{VSWR}-1}{Q_{t} \sqrt{\mathrm{VSWR}}} .
$$

Return loss is also given by

$$
S_{11}=-20 \log \left[\frac{\mathrm{VSWR}-1}{\mathrm{VSWR}+1}\right] .
$$

All previous equations for circular patch microstrip antenna printed on a cylindrical surface are function of the operating frequency which is variable of radius of curvature of the cylindrical body.

\section{Results}

In this paper, we have designed a circular path antenna resonating at $2.4 \mathrm{GHz}$ with a feeding point at the center. Two different types of Teflon material as a dielectric with height of $1.5 \mathrm{~mm}$ have been used as a substrate. Teflon is considered as an efficient substrate for its flexibility to conform on a cylindrical body [15]. Furthermore, the antenna performances are also calculated through simulation of a $5.24 \mathrm{~cm}$ radius circular path antenna conformed on $20 \mathrm{~cm}$ cylindrical body. Simulation was carried out using the FEKO 7.0 software from EMSS Inc.

3.1. Teflon Substrate. In this subsection, a Teflon material is used as a substrate with dielectric constant 2.1, tangent loss 0.0015 , and the patch radius $5.24 \mathrm{~cm}$. Figure 2 (a) illustrates the effect of changing the radius of curvature on the effective dielectric constant. As the curvature increases, the effective value of dielectric constant increases till it saturates. The radius of curvature is starting from $2 \mathrm{~cm}$ to $1 \mathrm{~m}$ to cover most of the change in curvature; after this value the effective dielectric constant tends to be constant as in the flat antenna. 


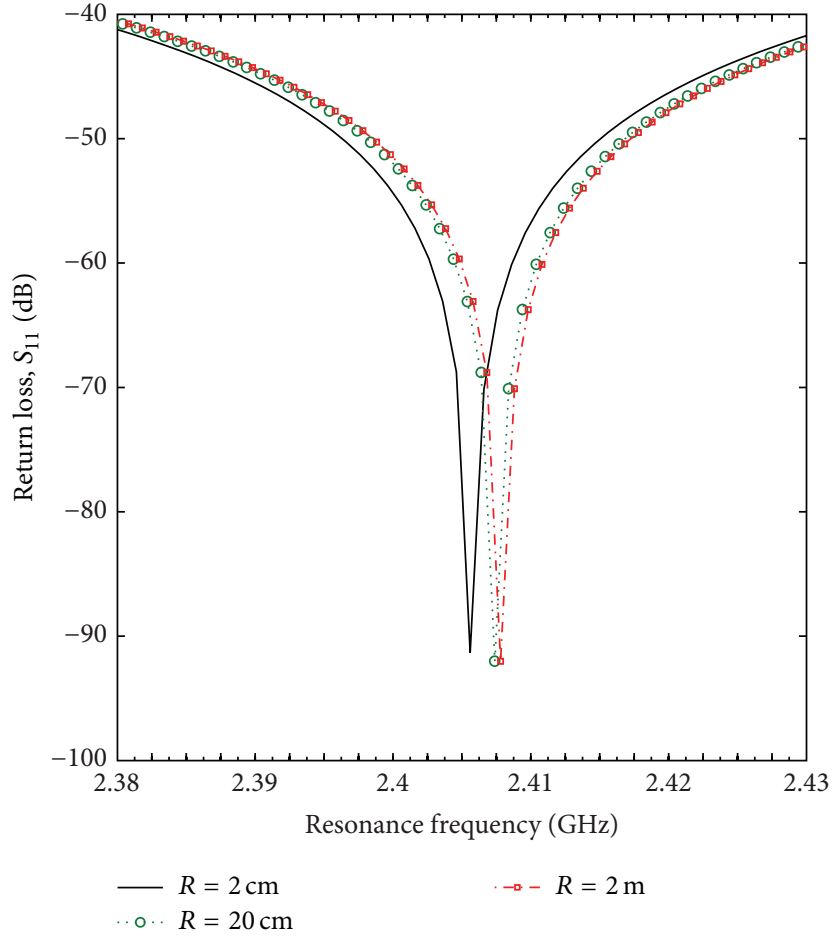

(a)

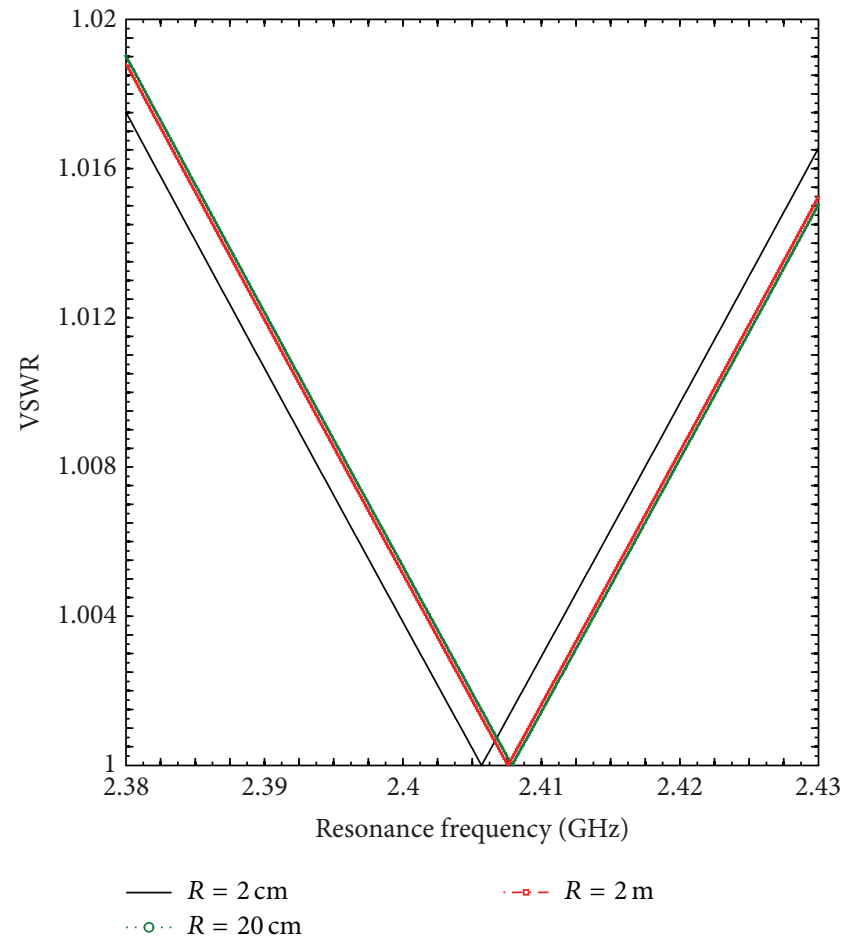

(b)

FIGURE 3: Impact of changing radius of curvature $(2 \mathrm{~cm}, 20 \mathrm{~cm}$, and $2 \mathrm{~m})$ of a circular microstrip patch (a) on the return loss in $\mathrm{dB}$ and (b) on the VSWR as a function of frequency. "Teflon substrate."

Impact of changing the radius of curvature on the resonance frequency is shown in Figure 2(b). There is a shift of $2 \mathrm{MHz}$ in frequency for the whole change in curvature $2 \mathrm{~cm}$ and flat antenna. This value is very small compared to resonance frequency. However, it is very important in multichannel applications such as ZigBee RF4CE. It operates at $2.4 \mathrm{GHz}$ and has a channel separation of $5 \mathrm{MHz}$. A small frequency shifting may lead to interference between channels.

Figure 3(a) shows the impact of changing the radius of curvature on the return loss as a function of frequency. The minimum values of $S_{11}$ are almost the same at $-91 \mathrm{~dB}$, but the minimum is shifted toward increasing the frequencies when the curvature decreases by the same values as shown in Figure 2(b). Figure 3(b) illustrates the change of VSWR as a function of curvature. The minimum value of VSWR is almost 1 , but the frequency is shifted.

Figures 4(a) and 4(b) show the normalized $H$-plane at $\varphi=$ $90^{\circ}$ and $270^{\circ}$ and $E$-plane at $\varphi=0^{\circ}$ and $180^{\circ}$ in $\mathrm{dB}$ as a function of curvature for $2 \mathrm{~cm}, 2 \mathrm{~m}$, and flat surface, respectively. It should be noted that the radiation pattern is getting wider as the curvature increased, which is expected for more bending of the body.

The radiation quality factor $Q_{\text {rad }}$, total quality factor $Q_{t}$, bandwidth $\mathrm{BW}$, and the real value of input impedance $R_{\text {in }}$ are calculated for different values of curvatures and listed in Table 1.

As radius of curvature increases, the value of $Q_{\text {rad }}$ decreases and consequently the $Q_{t}$ also decreases by a very
TABLE 1: $Q_{\text {rad }}, Q_{t}, B W$, and $R_{\text {in }}$ for different radius of curvatures.

\begin{tabular}{lccc}
\hline$R$ & $2 \mathrm{~cm}$ & $20 \mathrm{~cm}$ & $2 \mathrm{~m}$ \\
\hline$Q_{\text {rad }}$ & 67.5 & 67.4 & 67.37 \\
$Q_{t}$ & 1869 & 1868.7 & 1868.6 \\
$\mathrm{BW}(\mathrm{MHz})$ & 1.2929 & 1.2926 & 1.2925 \\
$R_{\text {in }}(\Omega)$ & 50.19 & 50.26 & 50.27 \\
\hline
\end{tabular}

small amount. There is a limited change in bandwidth about $400 \mathrm{~Hz}$ for a change in the radius of curvature from $2 \mathrm{~cm}$ to $2 \mathrm{~m}$. Small change in input impedance about $0.08 \Omega$ is also noted due to curvature change.

3.2. Epsilam-10 Ceramic-Filled Teflon Substrate. Epsilam10 ceramic-filled Teflon substrate material has a dielectric constant equal to 10 , tangent loss of 0.004 , and the patch radius is $2.45 \mathrm{~cm}$. The effect of changing the curvature of the cylindrical body on the effective dielectric constant and on the resonance frequency is illustrated in Figures 5(a) and 5(b), respectively.

It should be noted that $2.5 \mathrm{MHz}$ overall change in frequency is achieved corresponding to change in curvature between $2 \mathrm{~cm}$ radius and flat antenna. The change in frequency is lower than that of the Teflon material shown in Figure 2(b).

Figures 6(a) and 6(b) show $S_{11}$ and VSWR, respectively, as a function of frequency for different curvature. The minimum 


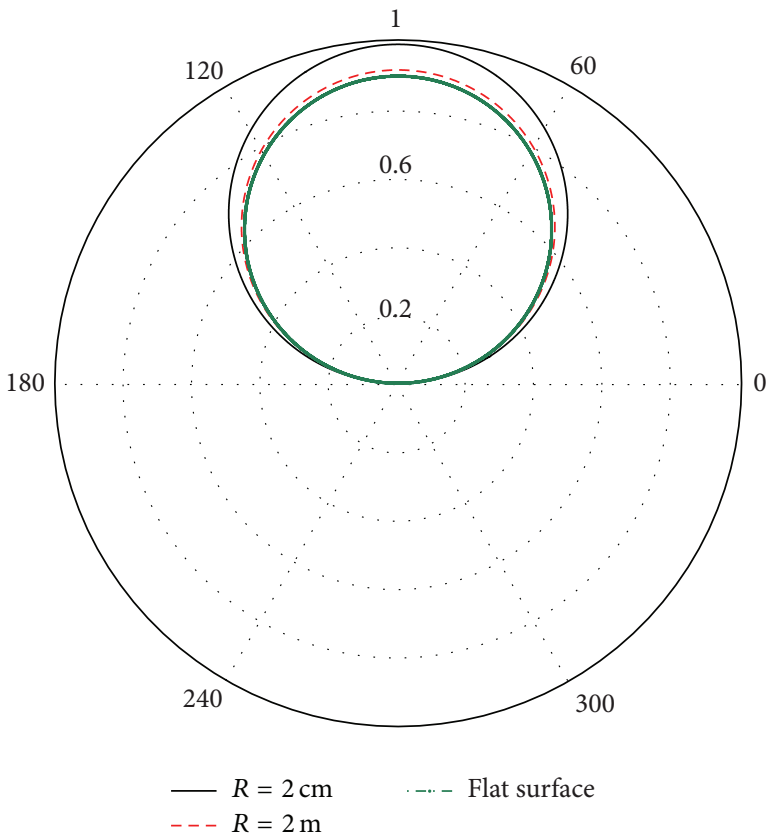

(a)

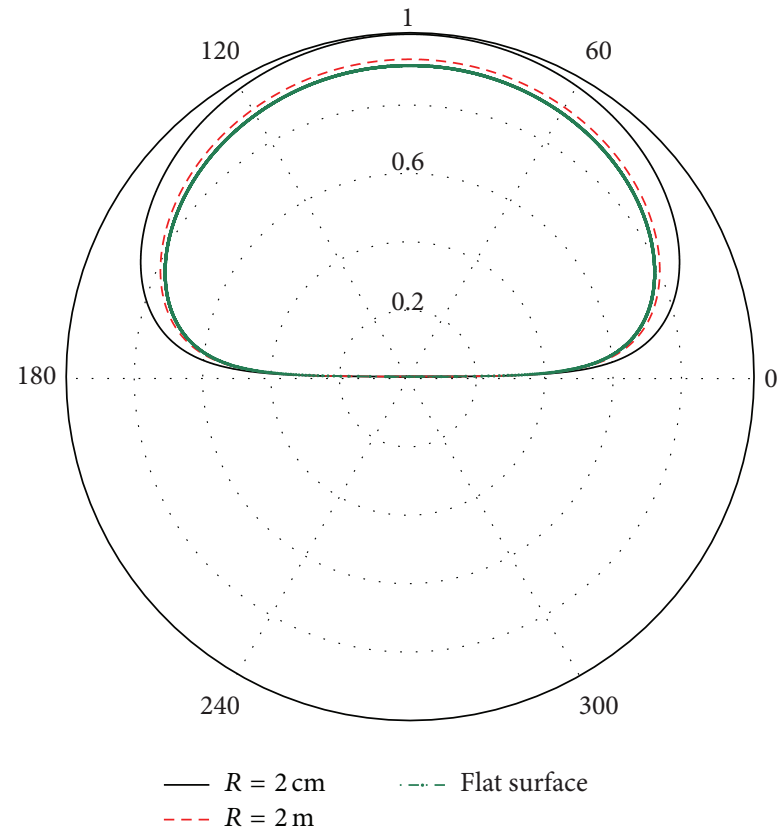

(b)

Figure 4: (a) Normalized $H$-plane $\left(\varphi=90^{\circ}, 270^{\circ}\right)$ and (b) normalized $E$-plane $\left(\varphi=0^{\circ}, 180^{\circ}\right)$ in $\mathrm{dB}$ at radii of curvature $2 \mathrm{~cm}, 2 \mathrm{~m}$ and flat surface. "Teflon substrate."

TABLE 2: $Q_{\text {rad }}, Q_{t}, B W$, and $R_{\text {in }}$ for different radius of curvatures.

\begin{tabular}{lccc}
\hline$R$ & $2 \mathrm{~cm}$ & $20 \mathrm{~cm}$ & $2 \mathrm{~m}$ \\
\hline$Q_{\text {rad }}$ & 411.5 & 410 & 409.7 \\
$Q_{t}$ & 2048.1 & 2047.5 & 2047.4 \\
$\mathrm{BW}(\mathrm{MHz})$ & 0.8642 & 0.864 & 0.862 \\
$R_{\text {in }}(\Omega)$ & 50.12 & 50.2 & 50.23 \\
\hline
\end{tabular}

values of $S_{11}(\approx-100 \mathrm{~dB})$ and VSWR $(1)$ are independent of the curvature. However, the frequencies corresponding to these minima are shifted. The location of the minimum increases with increasing the curvature and follows the behavior shown in Figure 5(b).

Figures 7(a) and 7(b) show the normalized $H$-plane at $\varphi=$ $90^{\circ}$ and $270^{\circ}$ and $E$-plane at $\varphi=0^{\circ}$ and $180^{\circ}$ in $\mathrm{dB}$ as a function of curvature for $2 \mathrm{~cm}, 2 \mathrm{~m}$, and flat surface. It should be noted that the radiation pattern is getting wider as the curvature increases. The radiation pattern of Epsilam-10 ceramic-filled Teflon substrate is wider than that of Teflon substrate shown in Figure 4.

Table 2 shows the radiation quality factor $Q_{\text {rad }}$, total quality factor $Q_{t}$, bandwidth BW, and the real values of input impedance $R_{\text {in }}$ for radius of curvatures values $2,20 \mathrm{~cm}$, and $2 \mathrm{~m}$. Similar to the case of using Teflon material as a substrate, $Q_{\text {rad }}$ and $Q_{t}$ decrease with an increase in the curvature. However, the changes in the bandwidth $(2.2 \mathrm{kHz})$ and in the input impedance $(0.11 \Omega)$ are higher than those achieved when Teflon material is used.
3.3. Simulation Results. In this subsection, using the MoM simulations, we thoroughly investigate the antenna performances including the return loss and VSWR of circular path antenna conformed on cylindrical body. Two different substrates (Teflon and Epsilam-10 ceramic-filled Teflon) were used. Results are compared to those obtained theoretically in the previous sections.

Figures 8 and 9 show the return loss and VSWR of a circular microstrip antenna conformed on a cylindrical body for $20 \mathrm{~cm}, 2 \mathrm{~cm}$, and $2 \mathrm{~m}$ using Teflon and Epsilam-10 ceramicfilled Teflon substrate, respectively.

The results from FEKO EM solver compare very favorably with our analytical results described in the paper. Difference in return loss at curvature radius of $2 \mathrm{~cm}$ and $2 \mathrm{~m}$ is almost $3.4 \mathrm{MHz}$ and $5 \mathrm{MHz}$ for the cases of Teflon, Figure $8(\mathrm{a})$, and Epsilam-10 ceramic-filled Teflon, Figure 9(a), substrate, respectively. These shifts are very close to the reported theoretical results.

However, the change in the minimum value of return loss and resonance frequency on this value may be attributed to the approximations taken into account through the analytical calculations and the software simulations as well.

\section{Conclusion}

The originality of this paper is to introduce the change in the resonance frequency of a circular patch microstrip antenna conformed on a cylindrical body. This frequency change is mainly due the modification of the effective dielectric constant with the curvature. We study the associated effects 


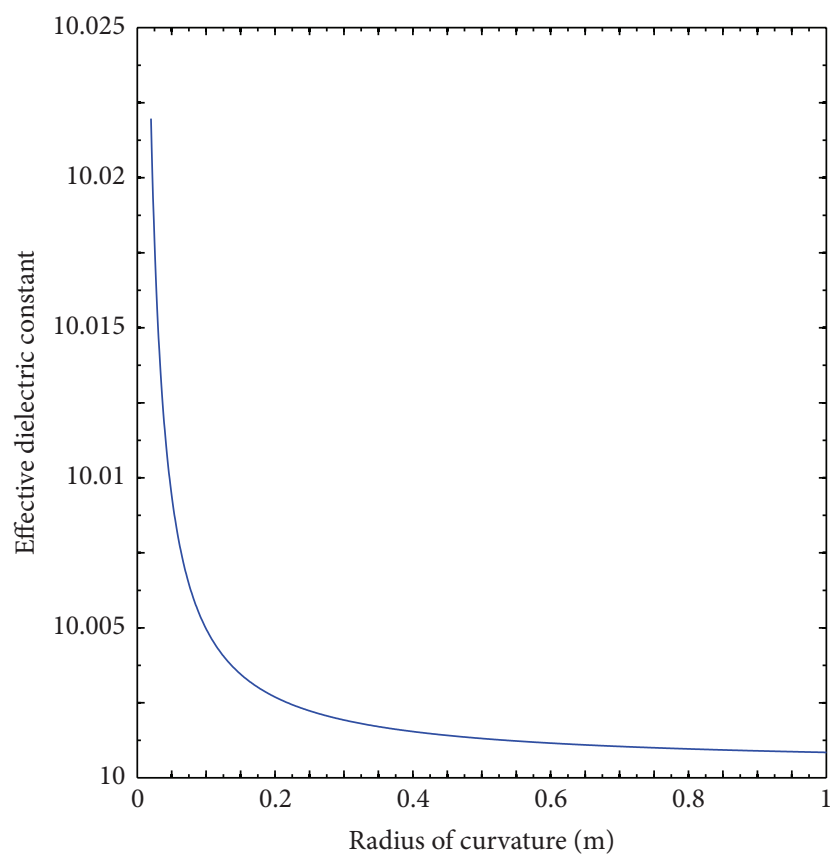

(a)

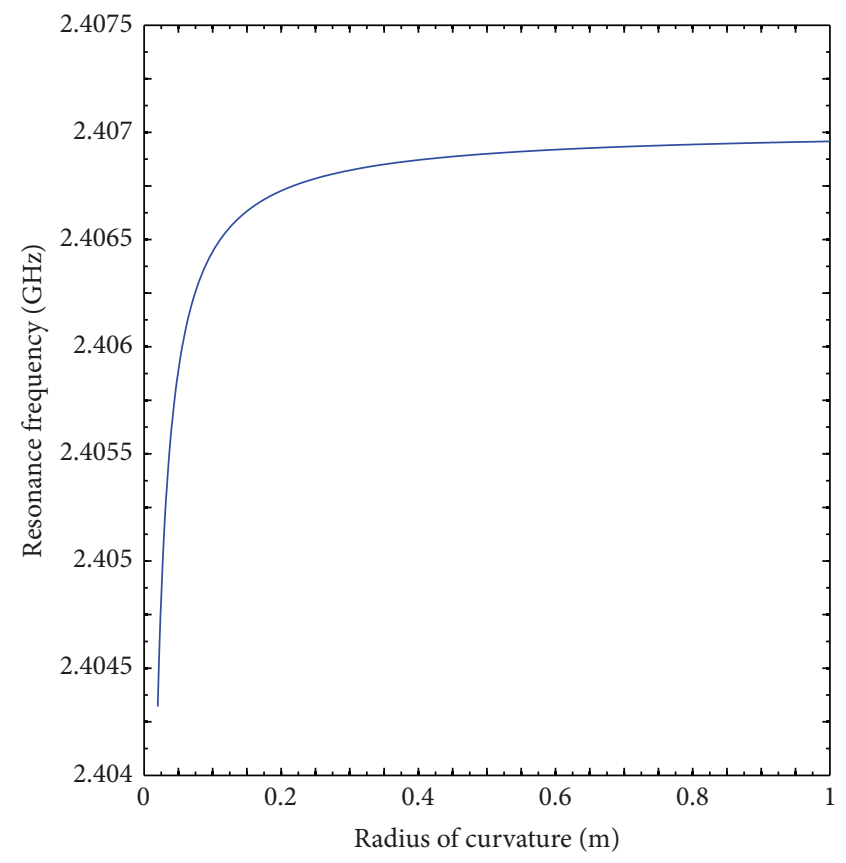

(b)

FIGURE 5: Impact of changing radius of curvature of a circular microstrip patch (a) on the effective dielectric constant and (b) on the resonance frequency. "Epsilam-10 ceramic-filled Teflon substrate."

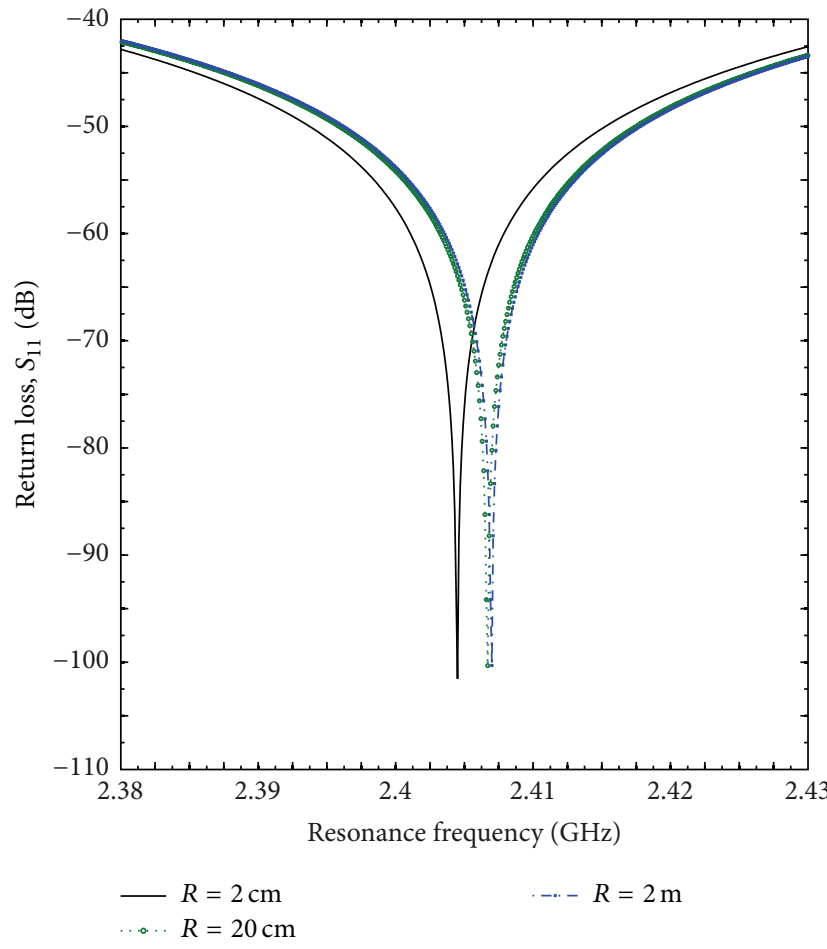

(a)

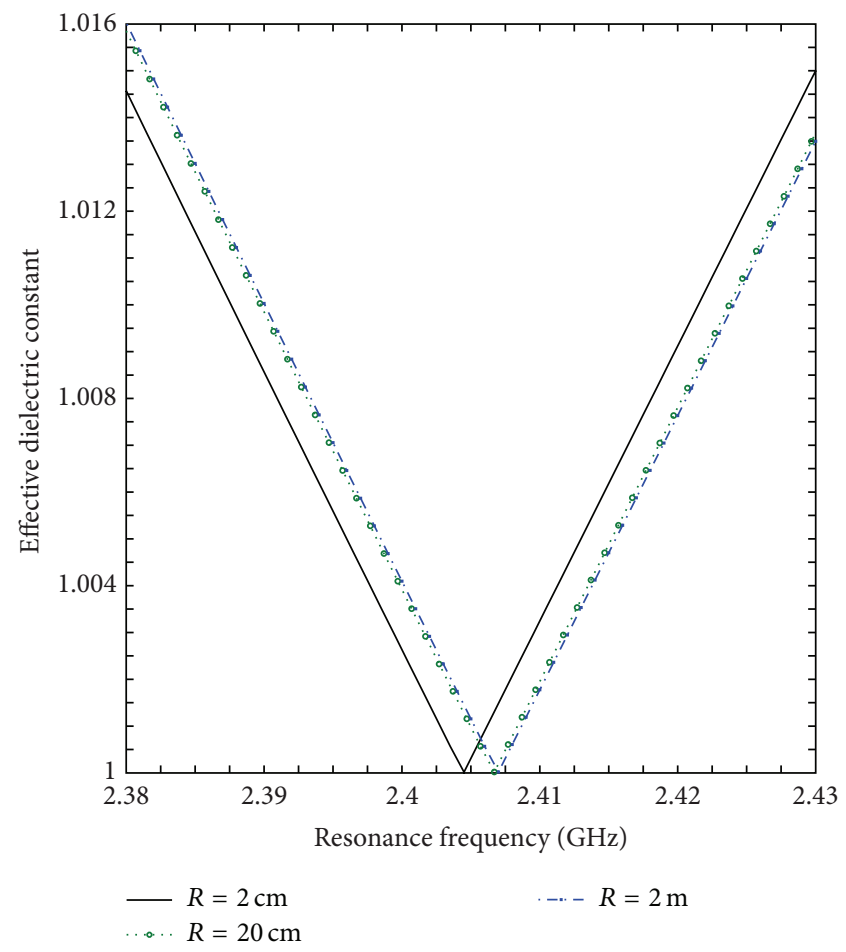

(b)

FIGURE 6: Impact of changing radius of curvature $(2 \mathrm{~cm}, 20 \mathrm{~cm}$, and $2 \mathrm{~m}$ ) of a circular microstrip patch (a) on the return loss in $\mathrm{dB}$ and (b) on the VSWR as a function of frequency. "Epsilam-10 ceramic-filled Teflon substrate." 


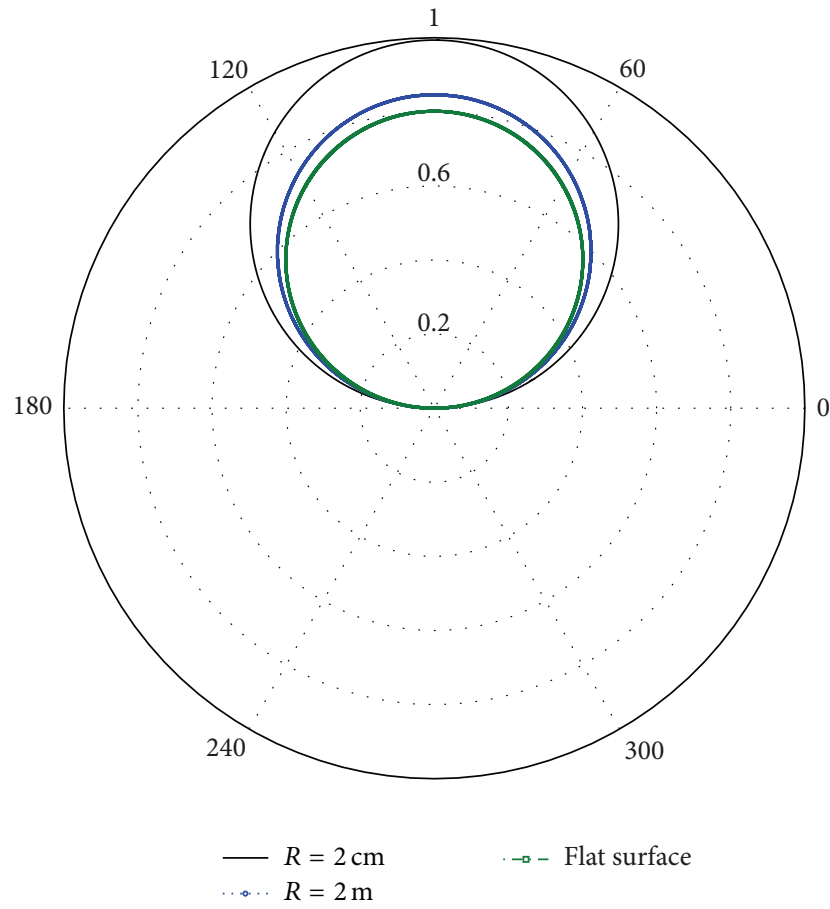

(a)

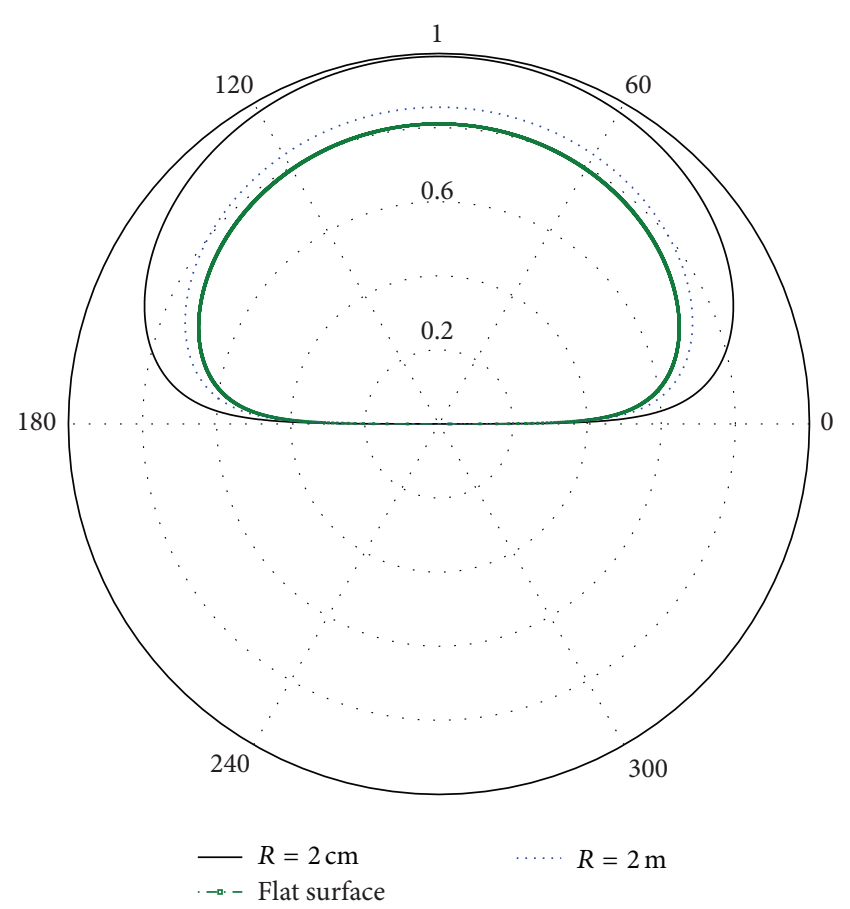

(b)

Figure 7: (a) Normalized $H$-plane $\left(\varphi=90^{\circ}, 270^{\circ}\right)$ and (b) normalized $E$-plane $\left(\varphi=0^{\circ}, 180^{\circ}\right)$ in $\mathrm{dB}$ at radii of curvature $2 \mathrm{~cm}, 2 \mathrm{~m}$ and flat surface. "Epsilam-10 ceramic-filled Teflon substrate."

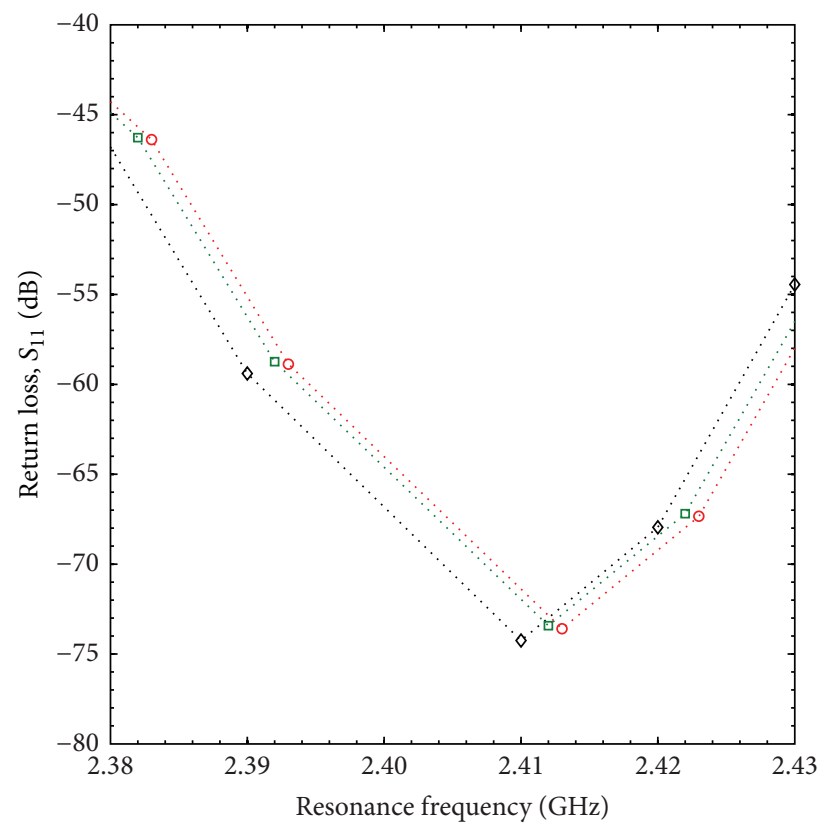

$\cdot \diamond \cdot R=2 \mathrm{~cm}$
$. \cdots R=20 \mathrm{~cm}$

(a)

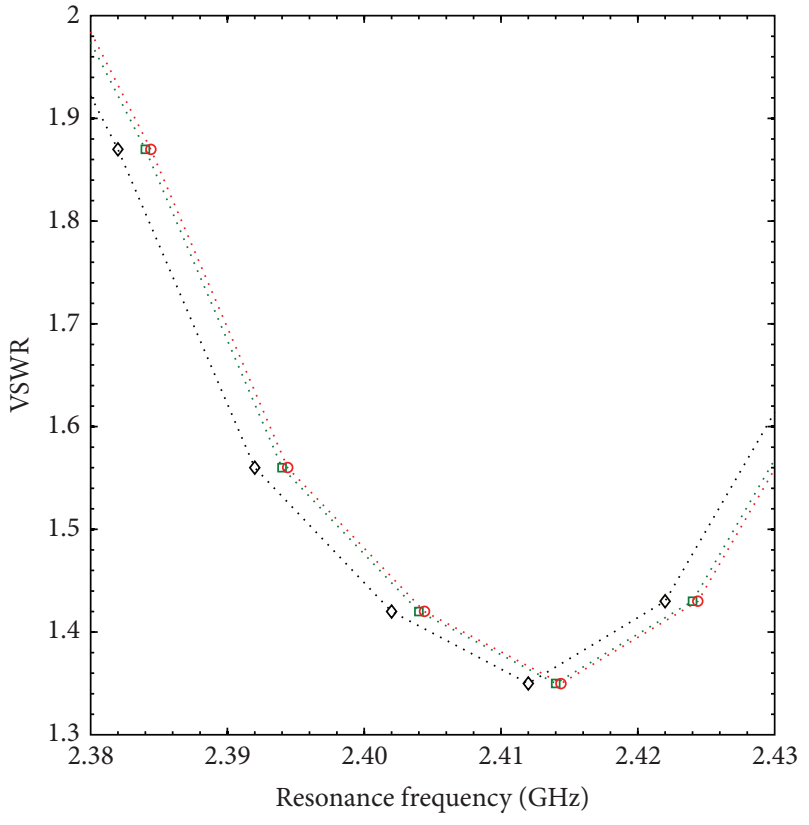
$\diamond \diamond \cdot R=2 \mathrm{~cm}$
o.. $R=2 \mathrm{~m}$

(b)

FIGURE 8: Impact of changing radius of curvature $(2 \mathrm{~cm}, 20 \mathrm{~cm}$, and $2 \mathrm{~m}$ ) of a circular microstrip patch (a) on the return loss in $\mathrm{dB}$ and (b) on the VSWR as a function of frequency. "Teflon substrate, FEKO". 


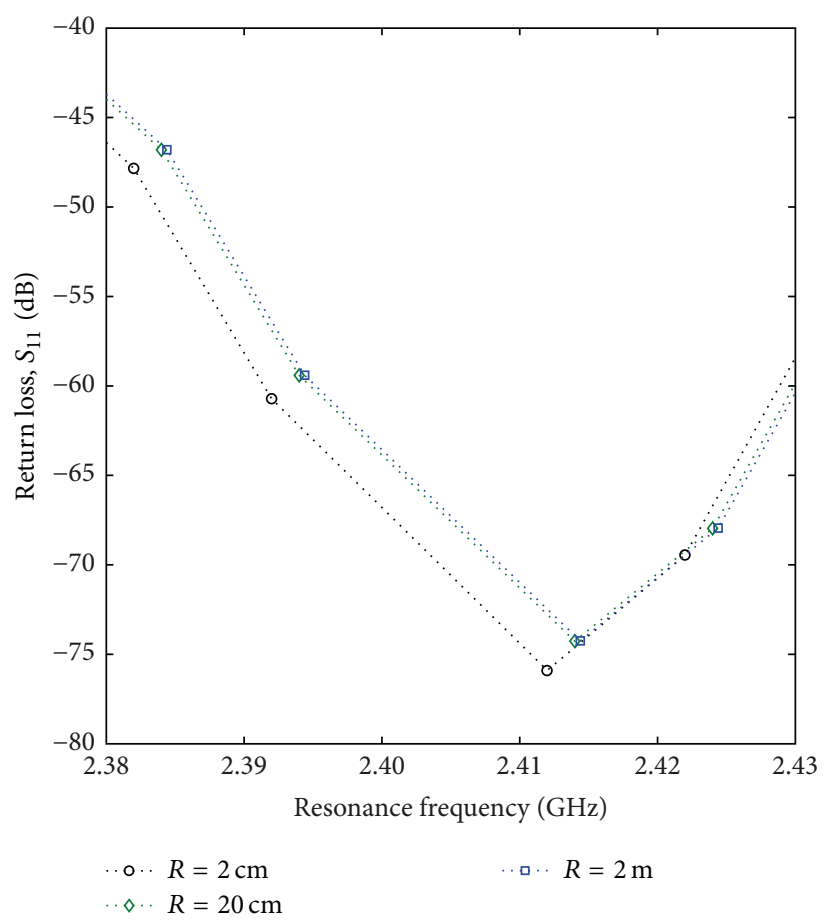

(a)

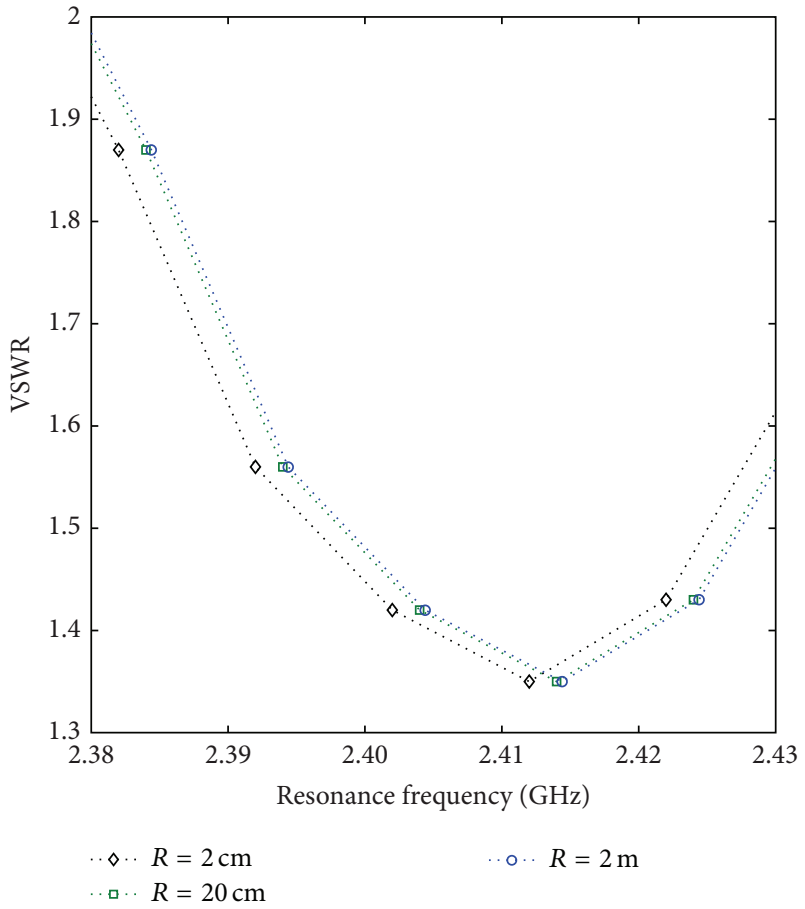

(b)

FIGURE 9: Impact of changing radius of curvature $(2 \mathrm{~cm}, 20 \mathrm{~cm}$, and $2 \mathrm{~m})$ of a circular microstrip patch (a) on the return loss in $\mathrm{dB}$ and (b) on the VSWR as a function of frequency. "Epsilam-10 ceramic-filled Teflon substrate, FEKO."

on some antenna parameters such as quality factor, input impedance, bandwidth, $S_{11}$, and VSWR at $\mathrm{TM}_{01}$ mode. Teflon and Epsilam-10 ceramic-filled Teflon are used as substrate materials with different dielectric constants. The resonance frequencies increased by $2 \mathrm{MHz}$ and $2.5 \mathrm{MHz}$ for a curvature change from $2 \mathrm{~cm}$ to $2 \mathrm{~m}$ for Teflon and Epsilam-10 ceramicfilled Teflon, respectively. Consequently, the VSWR and $S_{11}$ for both dielectric materials are shifted in frequency with increasing curvature of a cylindrical body. The change in input impedance is $0.08 \Omega$ for Teflon material and $0.11 \Omega$ for Epsilam-10 ceramic-filled Teflon material for curvature changing from $2 \mathrm{~cm}$ to $2 \mathrm{~m}$. The change in the bandwidth of Teflon and Epsilam-10 ceramic-filled Teflon is $2 \mathrm{kHz}$ and $2.2 \mathrm{kHz}$, respectively. Total quality factor is decreasing with increasing the curvature by very limited values for both substrate materials. The antenna performance was studied through simulation by using FEKO 7.0 software from EMSS Inc. The results from simulation compare very favorably with the described analytical results.

In general, the curvature has a limited effect on the performance of a circular patch microstrip printed antenna in the case of single channel. However, a small shifting in frequency will be very effective when a multichannel system is used. This will lead to a high change in VSWR and $S_{11}$ values.

\section{Conflict of Interests}

The authors declare that there is no conflict of interests regarding the publication of this paper.

\section{Acknowledgments}

This work was funded by the Deanship of Scientific Research (DSR), King Abdulaziz University, Jeddah, under Grant no. 965-302-D1435. The authors, therefore, acknowledge with thanks DSR technical and financial support. The author thanks Dr. I. Ashry for his help and information.

\section{References}

[1] Z. Zhang, G. Fu, S. Gong, S. Zuo, and Q. Lu, "Sleeve monopole antenna for DVB-H applications," Electronics Letters, vol. 46, no. 13 , pp. 879-880, 2010.

[2] A. Al-Zoubi, F. Yang, and A. Kishk, "A broadband center-fed circular patch-ring antenna with a monopole like radiation pattern," IEEE Transactions on Antennas and Propagation, vol. 57, no. 3, pp. 789-792, 2009.

[3] J. Liu, S. Zheng, Y. Li, and Y. Long, "Broadband monopolar microstrip patch antenna with shorting vias and coupled ring," IEEE Antennas and Wireless Propagation Letters, vol. 13, pp. 3942, 2014.

[4] J. Liu, Q. Xue, H. Wong, H. W. Lai, and Y. Long, "Design and analysis of a low-profile and broadband microstrip monopolar patch antenna," IEEE Transactions on Antennas and Propagation, vol. 61, no. 1, pp. 11-18, 2013.

[5] M. Abd-Elrazzak and I. Al-Nomay, "A design of circular microstrip patch antenna for bluetooth and HIPERLAN applications," in Proceedings of the 9th Asia-Pacific Conference on Communications (APCC '03), vol. 3, pp. 974-977, September 2003. 
[6] N. A. Zakaria, A. A. Sulaiman, and M. A. A. Latip, "Design of a circular microstrip antenna," in Proceedings of the IEEE International RF and Microwave Conference (RFM '08), pp. 289-292, Kuala Lumpur, Malaysia, December 2008.

[7] H. Rmili, J.-L. Miane, H. Zangar, and T. Olinga, "Design of microstrip-fed proximity-coupled conducting-polymer patch antenna," Microwave and Optical Technology Letters, vol. 48, no. 4, pp. 655-660, 2006.

[8] K. Wong, Design of Nonplanar Microstrip Antennas and Transmission Lines, John Wiley \& Sons, 1999.

[9] L. Josefsson and P. Persson, Conformal Array Antenna Theory and Design, Wiley-IEEE Press, 1st edition, 2006.

[10] A. Elrashidi, K. Elleithy, and H. Bajwa, "Conformal microstrip printed antenna," in Proceedings of the ASEE Northeast Section Conference, University of Hartford, West Hartford, Conn, USA, April 2011.

[11] C. Balanis, Antenna Theory, John Wiley \& Sons, New York, NY, USA, 2005

[12] A. Elrashidi, K. Elleithy, and H. Bajwa, "Effect of curvature on the performance of cylindrical microstrip printed antenna for $T M_{01}$ mode using two different substrates," International Journal of Computer Science and Information Security, vol. 9, no. 10, pp. 8-16, 2011.

[13] K.-F. Lee and K.-F. Tong, "Microstrip patch antennas-basic characteristics and some recent advances," Proceedings of the IEEE, vol. 100, no. 7, pp. 2169-2180, 2012.

[14] J. Chen, G. Fu, G.-D. Wu, and S.-X. Gong, "Application of broadband microstrip patch antenna as a perfect substitute for monopole antenna," in Proceedings of the International Conference on Microwave and Millimeter Wave Technology (ICMMT '10), pp. 321-324, Chengdu, China, May 2010.

[15] K. Luk and K. Lee, "On the cylindrical-circular patch antenna," in Proceedings of the Antennas and Propagation Society International Symposium, San Jose, Calif, USA, June 1989.

[16] K.-M. Luk and K.-F. Lee, "Characteristics of the cylindricalcircular patch antenna," IEEE Transactions on Antennas and Propagation, vol. 38, no. 7, pp. 1119-1123, 1990.

[17] A. Elrashidi, K. Elleithy, and H. Bajwa, "Conformal microstrip printed antenna," in ASEE Northeast Section Conference, University of Hartford, West Hartford, Conn, USA, April 2011.

[18] A. Elrashidi, K. Elleithy, and H. Bajwa, "A new analytical performance model for a microstrip printed antenna," in Proceedings of the ASEE Northeast Section Conference, University of Massachusetts Lowell, April 2012.

[19] H. Wheeler, "Transmission-line properties of parallel strips separated by dielectric sheet," IEEE Transactions on Microwave Theory and Techniques, vol. MTT-13, pp. 172-185, 1964.

[20] A. Elrashidi, K. Elleithy, and H. Bajwa, "The fringing field and resonance frequency of cylindrical microstrip printed antenna as a function of curvature," International Journal of Wireless Communications and Networking, vol. 3, no. 2, pp. 155-162, 2011.

[21] R. Richards, Time-Harmonic Electromagnetic Fields, McGrawHill, New York, NY, USA, 1961. 

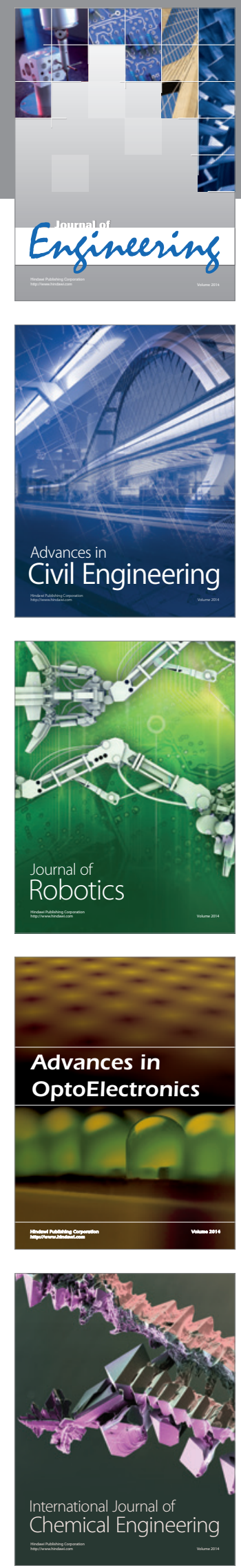

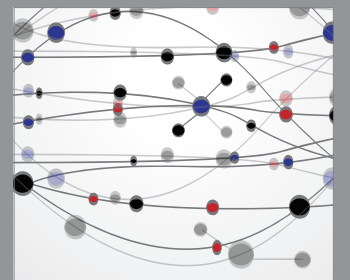

The Scientific World Journal
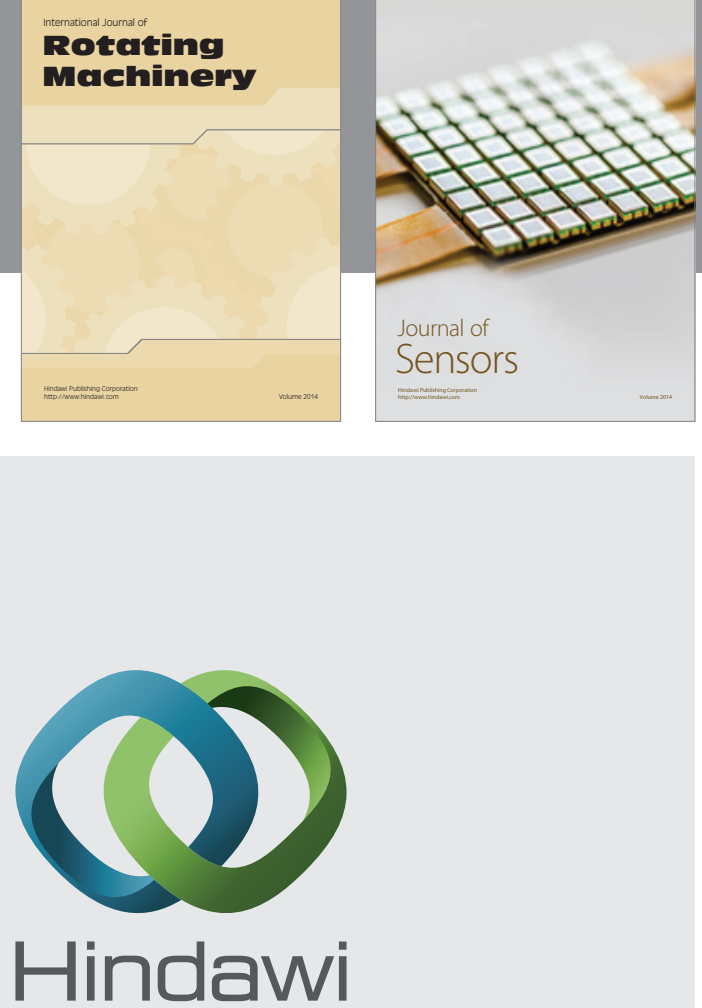

Submit your manuscripts at http://www.hindawi.com
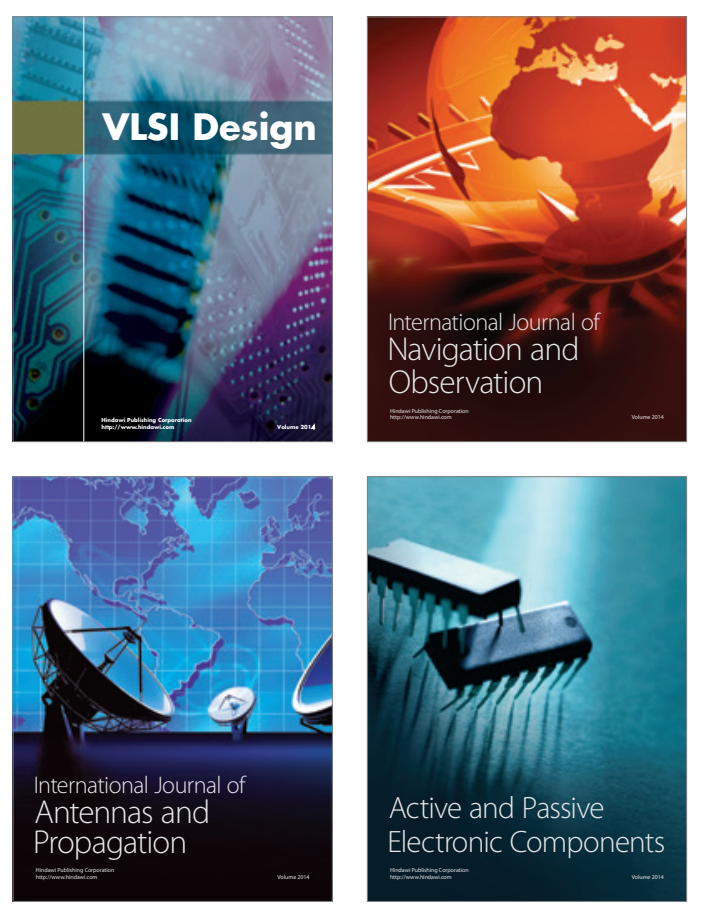
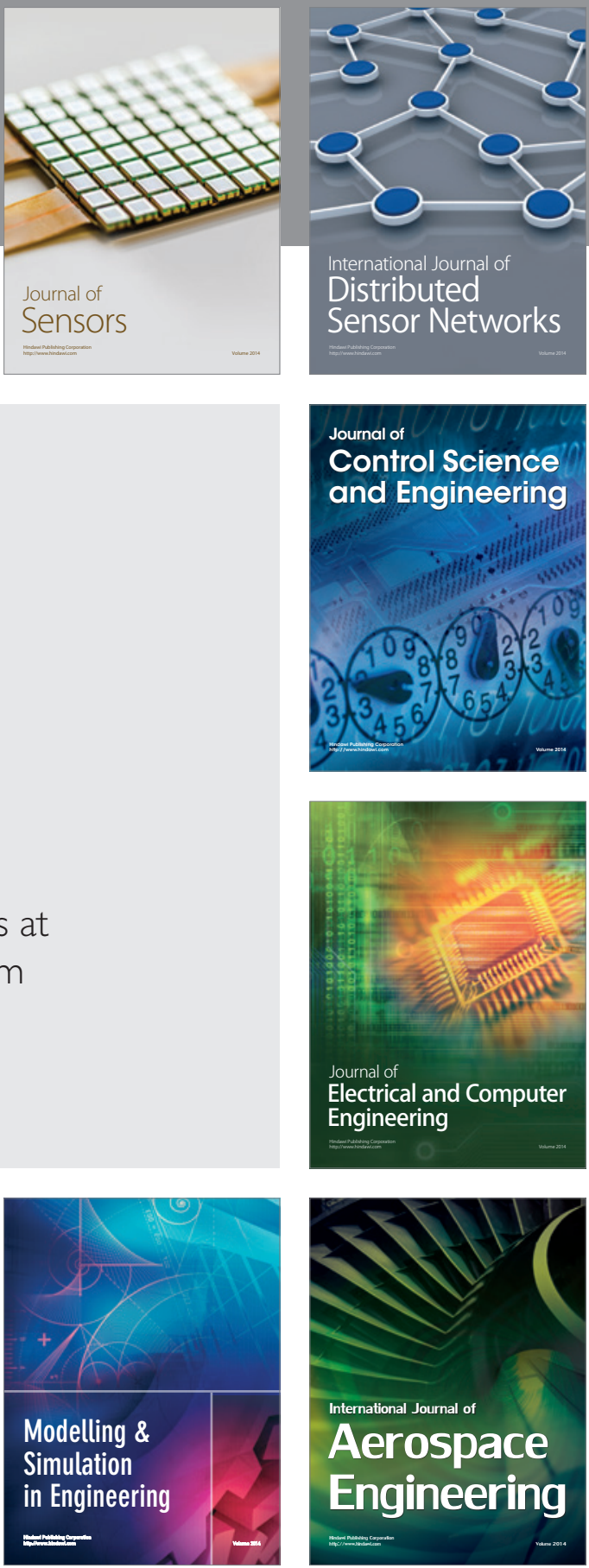

Journal of

Control Science

and Engineering
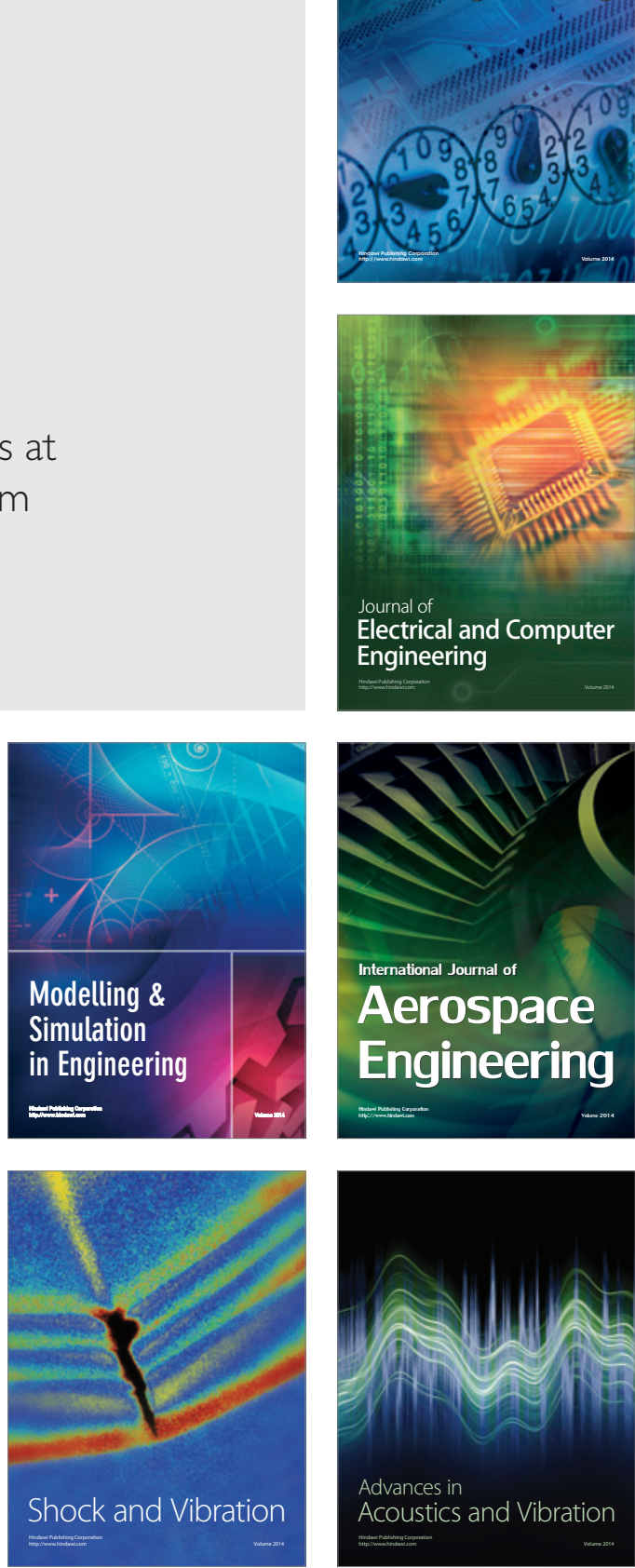